\title{
55. Using FILLER and VALUE
}

FILLER can be used instead of a dataname if you wish to set aside an area of storage but do not need to be able to refer to it by name. It is often used when setting out lines of text (in memory) ready for display on the screen or for output to a printer.

Each FILLER that you use is usually given a VALUE (often spaces) to indicate the contents of that memory area (and therefore how it will appear on the printout or screen).

$\begin{array}{lllll}\text { e.g. } 01 & \text { PRINT-HEADING. } & & \\ & 05 & \text { FILLER PIC } X(5) & \text { VALUE 'NAME'. } \\ & 05 & \text { FILLER PIC } X(20) & \text { VALUE } & \text { SPACES. } \\ & 05 & \text { FILLER PIC } X(4) & \text { VALUE 'MARK'. }\end{array}$

(Note that the word SPACES may be used to fill a data item with spaces).

When this item of data is DISPLAYed - the following will appear on the screen:

NAME

MARK

(Note the 20 spaces between the words).

Similarly a line of print may be set up with a mixture of variable data and fixed values.

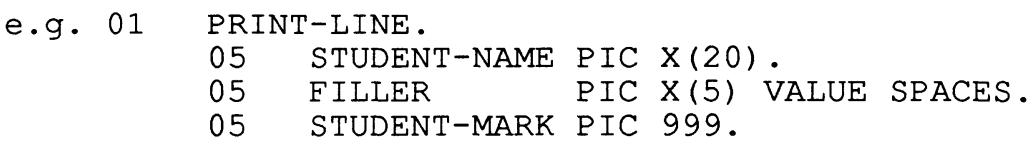

The name and mark can then be MOVEd from another area of store (possibly after READing them from a file) or ACCEPTed from the keyboard and then DISPLAYed in the form (e.g.):

JULIA 097

(Note how PRINT-LINE has been specified so that the items will line up under the headings in PRINT-HEADING).

The word FILLER itself may be omitted - e.g. 01 PIC X(5) VALUE SPACES.

\section{Exercise}

1. Write a program which will request a student's name, course title and grade - then display the information in one line with suitable spacing between each field.

2. Write a program which will display the heading:

EMPLOYEE NAME

then read the file 'staff' (created by the program you wrote as an exercise in lesson 46) and display each employee's details as a line of text - e.g.

WILLIAM SMITH

ANNE JONES

DAVID ANDREWS 